\title{
Genetic Dissection of Resistance to Common Rust (Puccinia Sorghi) in Tropical Maize (Zea mays L.) by Combined Genetic Mapping and Genomic Prediction
}

\section{Xuecai Zhang ( $\nabla$ xc.zhang@cgiar.org )}

CIMMYT: Centro Internacional de Mejoramiento de Maiz y Trigo

Jiaojiao Ren

Xinjiang Agricultural University

\section{Zhimin Li}

Henan Agricultural University

\section{Penghao Wu}

Xinjiang Agricultural University

\section{Alexander Loladze}

CIMMYT: Centro Internacional de Mejoramiento de Maiz y Trigo

Ao Zhang

Shenyang Agricultural University

Yubo Liu

Shenyang Agricultural University

\section{Guanghui Hu}

Heilongjiang Academy of Agricultural Sciences

\section{Shiliang Cao}

Heilongjiang Academy of Agricultural Sciences

Jingtao Qu

Sichuan Agricultural University

Hongjian Zheng

Shanghai Academy of Agricultural Sciences

\section{Michael Olsen}

CIMMYT: Centro Internacional de Mejoramiento de Maiz y Trigo

\section{Boddupalli M. Prasanna}

CIMMYT: Centro Internacional de Mejoramiento de Maiz y Trigo

\section{Felix San Vicente}

CIMMYT: Centro Internacional de Mejoramiento de Maiz y Trigo 


\section{Research article}

Keywords: Maize, common rust, genotyping-by-sequencing, genome-wide association study, linkage mapping, genomic prediction

Posted Date: December 16th, 2020

DOI: https://doi.org/10.21203/rs.3.rs-126178/v1

License: (c) (i) This work is licensed under a Creative Commons Attribution 4.0 International License. Read Full License 
4 Jiaojiao Ren ${ }^{1,2, \dagger}$, Zhimin $\mathrm{Li}^{2,3,1^{\dagger}}$, Penghao $\mathrm{Wu}^{1}$, Alexander Loladze ${ }^{2}$, Ao Zhang ${ }^{4}$, Yubo

$5 \mathrm{Liu}^{4}$, Guanghui $\mathrm{Hu}^{5}$, Shiliang $\mathrm{Cao}^{5}$, Jingtao $\mathrm{Qu}^{6}$, Hongjian Zheng ${ }^{7,8}$, Michael Olsen ${ }^{9}$,

6 Boddupalli M. Prasanna ${ }^{9}$, Felix San Vicente ${ }^{2}$, Xuecai Zhang $^{2,{ }^{*}}$

7

$8 \quad{ }^{*}$ Correspondence: xc.zhang@cgiar.org

$9 \quad$ Jiaojiao Ren and Zhimin Li contributed equally to this work.

$10{ }^{2}$ International Maize and Wheat Improvement Center (CIMMYT), El Batan, Texcoco 11 56237, México

12 Full list of author information is available at the end of the article 


\section{Abstract}

Background: Common rust is one of the major foliar diseases of maize, leading to significant grain yield losses and poor grain quality. The most sustainable strategy for controlling common rust is to develop resistant maize varieties, which requires a further understanding of genetic dissection of common rust resistance.

Results: In this study, an association panel and two bi-parental doubled haploid (DH) populations were used to perform genome-wide association study (GWAS), linkage mapping, and genomic prediction analyses. All the populations were phenotyped in multi-environment trials for common rust resistance and genotyped with genotyping-by-sequencing (GBS) single-nucleotide polymorphisms (SNPs). GWAS revealed six SNPs significantly associated with common rust resistance at bins 1.05, $1.10,3.04,3.05,4.08$, and 10.04, respectively. The SNP effect of each SNP ranged from 0.13 to 0.17 . Linkage mapping identified six quantitative trait loci (QTL) in the first DH population (DH1) and two QTL in the second DH population (DH2), distributed on chromosomes $1,2,3,4,6,7$, and 9, respectively. The phenotypic variation explained (PVE) of each QTL ranged from 3.55\% to $12.45 \%$. A new major QTL was detected in DH1 on chromosome 7 in the region between 144,585,945 and $149,528,489 \mathrm{bp}$, it had the highest LOD score of 7.82 and the largest PVE value of $12.45 \%$. The genomic regions located at bins $1.05,1.10$, and 4.08 were detected by both GWAS and linkage mapping. GRMZM2G114893 (bin 1.05) and GRMZM2G138949 (bin 4.08) were identified as the putative candidate genes conferring common rust resistance. The genomic prediction accuracies observed in 
the association panel and two bi-parental DH populations were 0.61, 0.51, and 0.10, respectively.

Conclusions: These results provided new insight into the genetic architecture of common rust resistance in maize and a better understanding of the application of genomic prediction for common rust resistance in maize breeding.

Keywords: Maize, common rust, genotyping-by-sequencing, genome-wide association study, linkage mapping, genomic prediction

\section{Background}

Common rust, caused by Puccinia sorghi, is one of the major foliar diseases of maize, which can cause as much as $49 \%$ yield loss in susceptible varieties [1]. Breeding for resistance is the preferred method for controlling common rust, which is the most cost-effective, environment-friendly, and sustainable approach [2]. Rossi et al. [3] reported six tropical lines from CIMMYT (International Maize and Wheat Improvement Center) highly resistant to common rust. Sserumaga et al. [4] identified 12 common rust resistant lines out of 50 tropical maize inbred lines. Those studies indicated the presence of genetic resistance to common rust in tropical maize germplasm. Genetic resistance to common rust can be divided into race-specific and partial resistance according to their specificity and durability [5]. Race-specific resistance is usually controlled by a single $\mathrm{R}$ gene and exhibits a high level of resistance to specific rust biotypes. More than 26 race-specific resistance (Rp) genes had been identified for common rust in complex loci on maize chromosomes $3,4,6$, 
and 10 [6-9]. The resistance of $\mathrm{Rp}$ genes could be breakdown easily due to high selection pressure. Partial resistance or quantitative disease resistance is often controlled by several genes and reduces the rate of fungal development on plant tissue [10]. It is race-nonspecific and tends to be more durable than race-specific resistance. Linkage mapping had been conducted for exploring quantitative trait loci (QTL) associated with partial resistance to common rust in Maize [8, 11, 12]. In four different European flint maize populations, Lübberstedt et al. [8] identified 20 QTL throughout the maize genome associated with partial resistance to Puccinia sorghi. Kerns et al. [11] identified 24 molecular markers in 16 chromosomal regions conferring partial resistance to common rust based on the single-factor analysis. In a sweet corn $\mathrm{F}_{2: 3}$ population derived from the cross of IL731a $\times \mathrm{W} 6786$, nine regions on 6 chromosomes related to partial common rust resistance were identified [12]. These QTL revealed by linkage mapping provides an opportunity for improving common rust resistance in maize through marker-assisted selection (MAS). However, the major QTL identified from different studies need to be validated further, and the mapping resolution also needs to be improved to detect the closely linked markers for MAS.

Genome-wide association study (GWAS) is a useful tool for identifying molecular markers significantly associated with the target trait and exploring the underlying candidate genes $[10,13,14]$. In an association panel consisted of 274 maize inbred lines, three loci associated with common rust resistance were identified, and the candidate genes detected in this study had predicted roles in cell wall modification and in regulating the accumulation of reactive oxygen species [10]. This study 
suggested that GWAS is a powerful approach for identifying the genomic regions associated with the common rust resistance in maize, it has high genetic mapping resolution, because of the abundant genetic diversity and faster linkage disequilibrium decay in maize [15]. However, the use of GWAS was limited by false-positive or false-negative due to population structure and familial relationships [16]. The combined use of GWAS and linkage mapping become a more powerful approach for exploring candidate loci associate with complex quantitative traits due to higher mapping resolution and greater statistical power. This combined method has been widely used to detect the genetic basis of complex quantitative traits in maize, such as plant and ear height [17], male inflorescence [18], amino acids in maize kernel [19], tar spot complex resistance [20], common rust resistance [9] and maize chlorotic mottle virus and maize lethal necrosis resistance [21]. In a joint GWAS and linkage mapping analysis, GWAS analysis identified 37 SNPs significantly associated with the common rust resistance, and linkage mapping analysis detected five QTL conferring the common rust resistance [9]. Nine candidate genes were identified, which are metabolic or signaling genes involved in the disease resistance. Kibe et al. [22] revealed 14 significant SNPs associated with common rust in an association panel and 26 QTLs in five $F_{3}$ populations.

Genomic prediction (GP) is an extension of MAS that uses genome-wide markers to predict the genomic estimated breeding values (GEBVs) of the un-phenotyped lines for selection [23]. GP has been reported in many studies to accelerate the genetic gain in plant breeding programs [20, 24-27]. The GP accuracy of common rust resistance 
was first reported by Kibe et al. [22] which ranged from 0.19 to 0.51 in different populations. Cao et al. [20] reported that the GP accuracy of tar spot complex resistance ranged from 0.55 to 0.74 in different populations. The GP accuracy of maize lethal necrosis disease resistance was 0.56 in the IMAS-AM panel and 0.36 in the DTMA-AM panel, respectively [24]. The moderate to high prediction accuracy on complex diseases indicates that GP has the potential to improve maize disease resistance.

Genotyping-by-sequencing (GBS), the next-generation sequencing technology, enables efficient genotyping of a large number of individuals for a large number of SNPs at a low per-sample cost. The high-throughput, robust, and cost-effective sequencing approach has been applied in genetic studies, such as linkage mapping, GWAS, and GP in diverse plant species [28]. Marker density is an important factor for improving the mapping resolution. Previous studies showed that the resolution of genotyping mapping researches was improved by 50\% using the high-density GBS SNPs $[29,30]$.

In this study, an association panel and two bi-parental DH populations were used to perform GWAS, linkage mapping, and genomic prediction analyses, where all the populations were phenotyped in multi-environment trials for common rust resistance and genotyped with genotyping-by-sequencing (GBS) single-nucleotide polymorphisms (SNPs). The main objectives of the present study were to detect the significantly associated SNPs, QTL, and putative candidate genes associated with common rust resistance in tropical maize by joint linkage analysis and GWAS, and 
explore the potential of GP to improve maize tolerance to common rust.

\section{Results}

\section{Phenotypic variations}

The descriptive statistics for resistance to common rust in the DTMA (Drought Tolerant Maize for Africa) panel and the two bi-parental DH populations are presented in Table 1 and Figure 1a. The results indicated that there were abundant phenotypic variations in each population. For example, the DTMA panel showed the greatest phenotypic variation, where common rust scores ranged from 1.26 to 4.13 on

a 1 to 5 disease scale. The means of disease score were 2.32, 2.25, and 2.27 in DTMA panel, DH1, and DH2, respectively. Mixed model analysis of common rust resistance revealed significant $(p<0.01)$ genotypic variance $\left(\sigma_{g}^{2}\right)$ in all three populations. The genotype by environment interaction variance $\left(\sigma_{g e}^{2}\right)$ was significant $(\mathrm{p}<0.01)$ in the DTMA panel and DH1, but not in DH2. Broad-sense heritability estimated was 0.80 in DTMA panel, 0.57 in DH1, and 0.84 in DH2. High heritability indicated that most of the variation among inbred lines can be attributed to genetic variation and suitable for QTL analysis.

\section{Genotypic data analysis}

The basic information about GBS data before and after filtering is shown in Table 2. After filtering, the number of SNPs decreased from 955690 to 187409 in the imputed dataset of DTMA panel, while in the un-imputed datasets of DH1 and DH2, the number of SNPs decreased from 955690 to 31194 and 37985, respectively. Before 
filtering, the missing rate in the imputed dataset of the DTMA panel was only $16.79 \%$, which was much lower than that in the un-imputed datasets of DH1 $(42.53 \%)$ and DH2 (42.29\%). After filtering, the missing rate was similar in imputed and un-imputed datasets, ranging from $7.33 \%$ to $9.73 \%$. The heterozygosity rate of all three populations increased after filtering. The average MAF increased from $9.28 \%$ to $18.01 \%$ in the imputed dataset of DTMA panel after filtering. In the two bi-parental DH populations, the average MAF increased to $42.04 \%$ and $42.01 \%$ after filtering, close to the expected allele frequency of $50 \%$.

\section{Linkage disequilibrium and population structure}

The imputed GBS data was used to calculate linkage disequilibrium (LD) decay distance in the DTMA panel. The average LD decay distance across all the 10 chromosomes with an $r^{2}$ value of 0.1 was $8.14 \mathrm{~kb}$ (Figure 2). LD decay distance ranged from $4.57 \mathrm{~kb}$ in chromosome 10 to $15.9 \mathrm{~kb}$ in chromosome 8 .

Population structure analysis showed that the delta $K$ value reached a peak when the $K$ value was 4 , indicating that the DTMA panel can be divided into four subgroups (Figure 3). Subgroup 1 was the largest consisted of 219 lines. The number of lines in subgroup 2, 3, and 4 was 13,10 , and 40 , respectively. Figure $1 \mathrm{~b}$ showed different responses to common rust in the four subgroups.

\section{Genome-wide association study}

The GWAS results of the DTMA panel are presented in Table 3 and Figure 4. The best linear unbiased predictors (BLUPs) obtained from META-R were used as 
164

phenotypes for GWAS. A total of 6 SNPs at bins 1.05, 1.10, 3.04, 3.05, 4.08, and 10.04 were identified to be significantly associated with common rust resistance using the FarmCPU (Fixed and random model Circulating Probability Unification) model in GAPIT (Genome Association and Prediction Integrated Tool-R package).

Two significant SNPs, S1_89238026 and S1_278132829, were identified at bins 1.05 and 1.10 on chromosome 1 . The most significant SNP S1_278132829 ( $P$-value $7.25 \times 10^{-11}$ ) had a MAF of 0.25 and a SNP effect of 0.13 . It was located within the candidate gene of GRMZM2G328500 (278,126,093 - 278,132,841 bp), which encodes a UDP-glucose 6-dehydrogenase. SNP S1_89238026 $\left(P\right.$-value $\left.9.81 \times 10^{-10}\right)$ was the second most significant marker. It had a MAF of 0.32 and a SNP effect of 0.13 . It is associated with the candidate gene of GRMZM2G114893 $(89,236,681-89,237,918 \mathrm{bp})$ encoding a Zinc finger $\left(\mathrm{C}_{2} \mathrm{H}_{2}\right.$ type $)$ family protein.

Two other SNPs, S3_118933375 and S3_147594533, with significant $P$-values were mapped on chromosome 3. SNP S3_118933375 with SNP effect of -0.17 was $587 \mathrm{bp}$ away from the candidate gene of GRMZM2G144004 (118,931,829 $118,932,788$ bp). The second SNP S3_147594533 was located at the candidate gene of GRMZM2G162250 (147,591,043 - 147,598,482 bp), which encodes for a Zea mays ARGOS6 protein. The MAF of the two SNPs was only 0.10 and 0.11 , respectively.

On chromosome 4, SNP marker of S4_183913302 was located close to the candidate gene of GRMZM2G138949 (183,909,192 - 183,910,514 bp). This gene encodes a BTB/POZ domain-containing protein. Significant maker of S10_95231291 
185

186

187

188

189

190

191

192

193

194

195

196

197

198

199

200

201

202

203

linked with the candidate gene of GRMZM2G131536 (95,230,282 - 95,231,024 bp)

was located on chromosome 10 at position 95,231,291 bp.

\section{Linkage mapping analysis}

Linkage mapping results of the two bi-parental $\mathrm{DH}$ populations are presented in Table 4 and Figure 5. Six QTL located on chromosomes 1, 2, 4, 6, 7, and 9 were identified in DH1. The phenotypic variance explained by a single QTL ranged from $3.55 \%$ to $12.25 \%$. The total phenotypic variance explained by all the six QTL was $44.22 \%$. The common rust resistance alleles were derived from the resistant inbred line of CML495, except for the two QTL on chromosomes 1 and 9. The QTL on chromosome 7 had the highest LOD score of 7.82, indicating that this is a major QTL for common rust resistance. Two QTL on chromosomes 1 and 3 were detected in DH2. The two QTL had small effects, explaining $8.33 \%$ and $8.80 \%$ of the total phenotypic variation, respectively. Resistance alleles for both QTL were derived from the resistant parental line of CML451.

\section{Genomic prediction for common rust}

GP results of the DTMA panel and the two bi-parental DH populations were presented in Figure 6. The GP accuracies estimated in the DTMA panel, DH1, and DH2 were $0.61,0.51$, and 0.10 , respectively. Compared with $\mathrm{DH} 1$, the prediction accuracy of DH2 was especially low.

\section{Discussion}

\section{Joint GWAS and linkage mapping}


Linkage mapping and GWAS are two powerful approaches for exploring the genetic basis of complex quantitative traits [9, 20]. Linkage mapping is always conducted in bi-parental populations with a low resolution of 10-30 cM, which is 209 limited by recombination events occurring in the development of mapping populations [31, 32]. GWAS based on genetic linkage disequilibrium provides higher resolution and greater ability to detect genetic variations associated with the trait [33, 34]. However, GWAS are constrained by population structure and familial relationships, which can lead to false-positive or false-negative associations [35]. 

identified in previous studies $[8,10,22]$. The major QTL located on chromosome 7 was reported here for the first time, it had the highest LOD score of 7.82 and largest PVE value of $12.45 \%$ in the present study. In DH2, two small-effect QTL were mapped on chromosomes 1 and 3, respectively. The QTL in bin 1.10 was also reported by Lübberstedt et al. [8]. All the QTL identified in DH1 and DH2 were environments [36]. due to the very low frequency of one of the alleles of the relevant locus in the 
association panel or population structure is related to the polymorphism at this locus $[37,38]$.

\section{Candidate gene analysis for common rust resistance}

Candidate gene analysis can lead to a better understanding of the genetic basis of common rust resistance. A total of six candidate genes were identified in this study (Table 3). GRMZM2G328500 encodes a UDP-glucose 6-dehydrogenase, which is involved in the nucleotide-sugar interconversion process [39]. GRMZM2G162250 encodes a Zea mays ARGOS6 (auxin regulated gene involved in organ size) protein controlling plant growth, organ size, and grain yield.

GRMZM2G114893 encodes a zinc finger $\left(\mathrm{C}_{2} \mathrm{H}_{2}\right.$ type $)$ family protein. Zinc finger protein is a kind of transcription regulator with a finger domain. Zinc finger $\left(\mathrm{C}_{2} \mathrm{H}_{2}\right.$ type) family protein is a type of zinc finger protein with two $\mathrm{Cys}_{2} / \mathrm{His}_{2}$-type motifs. It has been studied in many plant species, which was mainly involved in the regulation of plant growth, development, and tolerance to biotic and abiotic stresses [40-42]. Under abiotic stresses, such as cold, drought, salt, osmotic, and oxidative, the transcription level of many $\mathrm{C}_{2} \mathrm{H}_{2}$ type zinc finger proteins is increased [43]. In tobacco transgenic plants, overexpressing the ZFT1 gene showed increased tobacco mosaic virus tolerance [44]. Transgenic Arabidopsis plants overexpressing CAZFP1 not only increased drought tolerance but also increased resistance against Pseudomonas syringae pv. tomato infection [45]. In conclusion, the $\mathrm{C}_{2} \mathrm{H}_{2}$ type zinc 
finger protein plays an important role in plant biotic and abiotic stress responses. GRMZM2G114893 is a possible candidate gene for common rust resistance.

Candidate gene GRMZM2G138949 identified in bin 4.08 encodes a BTB/POZ domain-containing protein. The $\mathrm{BTB} / \mathrm{POZ}$ domain is an evolutionarily conserved and widely distributed domain, which participates in a series of physiological and biochemical reactions and also plays an important role in resistance to plant disease. The Arabidopsis NPR1 gene encodes a BTB/POZ domain-containing protein that controls systemic acquired resistance (SAR) [46]. In rice transgenic plants, overexpressing a rice NPR1 homolog (NH1) leads to enhanced resistance to Xanthomonas oryzae pv. oryzae [47]. Ectopic expression of the Arabidopsis NPR1 gene in strawberry leads to enhanced resistance to angular leaf spot, powdery mildew, and anthracnose [48]. GRMZM2G138949 is the most likely candidate gene for common rust resistance in maize.

\section{Genomic prediction}

GP is a useful tool to accelerate genetic gain in breeding programs. Genome-wide molecular markers were used to predict the breeding values of lines for selection [49]. The GP accuracy might be influenced by many factors, such as marker density, training population size, genetic architecture and heritability of target traits, the relationship between the training and prediction populations [20, 50]. In this study, GP for common rust resistance has been conducted in a DTMA panel and two bi-parental DH populations with SNPs derived from GBS. The GP accuracies varied 
across populations and ranged from 0.10 to 0.61 , which were consistent with the results of Kibe et al. [22] $(0.10-0.51)$. The highest accuracy was estimated in the DTMA panel. This may be due to the large population size, high heritability, and great genetic diversity. Although the broad-sense heritability of $\mathrm{DH} 2$ was up to 0.84 , the prediction accuracy of DH2 was only 0.10 . The significant difference in prediction accuracy between the two bi-parents DH populations may be due to the differences in genetic diversity and population size. In DH2, only two small-effect QTL contributed $17.13 \%$ of the phenotypic variance were identified and no major QTL was identified.

\section{Conclusions}

In this study, we used an association mapping panel and two bi-parental DH populations genotyped with GBS SNPs and phenotyped for common rust resistance in multi-environment trials to understand the genetic architecture of common rust resistance in maize. A total of 6 SNPs were detected by GWAS and 8 QTL were identified by linkage mapping. Three significant SNPs at bins 1.05, 1.10, and 4.08 were verified through linkage analysis. A major QTL located on chromosome 7 was identified in DH1. Candidate genes of GRMZM2G114893 encoding a Zinc finger $\left(\mathrm{C}_{2} \mathrm{H}_{2}\right.$ type $)$ family protein and GRMZM2G138949 encoding a BTB/POZ domain-containing protein were considered as the putative genes associated with common rust resistance in maize. Joint GWAS and linkage mapping results indicated that common rust resistance is controlled by multiple QTL with small to medium effects. This study provides new insights into the potential of GP to improve maize 
common rust resistance, which could help to better understand the application of genomic prediction in maize breeding for complex disease resistance.

\section{Methods}

\section{Plant materials}

An association mapping panel of 282 genetic diverse inbred lines was used for GWAS and GP in the present study. The association mapping panel, DTMA (Drought Tolerant Maize for Africa), was collected by the Global Maize Program of CIMMYT. Based on the geographic information and environmental adaptation, the DTMA panel was classified into eight subsets: (1) Mexico physiology breeding program; (2) Mexico entomology breeding program; (3) Mexico lowland tropical breeding program; (4) Mexico highland tropical breeding program; (5) Colombia subtropical breeding program; (6) Zimbabwe subtropical breeding program; (7) Nigeria breeding program; and (8) Ethiopia breeding program.

Two bi-parental doubled haploid (DH) populations were used for linkage mapping and GP. The first DH population (DH1) developed from inbred lines CML495 and La Posta Sequia C7 F64-2-6-2-2-B-B-B, was consisted of 189 DH lines. The second DH population (DH2) developed from inbred lines CML451 and DTPYC9-F46-1-2-1-2-B-B-B, was consisted of 115 DH lines. CML495 and CML451 are common rust-resistant lines, and the other two parental lines are common rust susceptible lines. The seeds used to set up experiments for this study were originally acquired from the Global Maize Program of CIMMYT. 


\section{Experimental design}

All of the three populations were evaluated for response to common rust at CIMMYT's experimental station in Mexico. The DTMA panel was evaluated at Agua Fria in 2008, 2009, 2010, and 2012. DH1 was evaluated at El Batan and Santa Catarina in 2013. DH2 was evaluated at Agua Fria in 2011 and El Batan in 2013. All the locations have high and consistent natural expressions of common rust. A randomized complete block design with three replications was used for all trials. Each plot consisted of 11 plants in a $2 \mathrm{~m}$ row with a width of $0.75 \mathrm{~m}$.

\section{Disease evaluation}

Plants were visually evaluated for common rust three times at 7-day intervals, beginning two weeks after flowering. Disease severity was evaluated on a 1-5 scale based on the percentage of leaf area covered by lesions. A rating scale of 1 corresponds to high resistance, 2 corresponds to weak to moderate infection covering $0-20 \%$ of the leaf surface, 3 corresponds to moderate infection covering $21-50 \%$ of the leaf surface, 4 corresponds to moderate-to-severe infection covering $51-80 \%$ of the leaf surface, and 5 corresponds to severe infection covering $>80 \%$ of the leaf surface. For each plot, the final highest score was used for further analysis.

\section{Phenotypic data analysis}

The multi-environment trial analysis was conducted using META-R Version 6.04 (http://hdl.handle.net/11529/10201). A mixed linear model was used to calculate the best linear unbiased predictors (BLUPs), variance components, and broad-sense 
heritability. The model used for data analysis was as follow:

$$
\mathrm{Y}_{i j k}=\mu+\mathrm{E}_{i}+\mathrm{R}_{j(i)}+\mathrm{G}_{k}+\mathrm{EG}_{i k}+\varepsilon_{i j k}
$$

Where $\mathrm{Y}_{i j k}$ is the observation of the $k$ th genotype in the $i$ th environment in the $j$ th replicate; $\mu$ is the overall mean; $\mathrm{E}_{i}$ is the effect of the $i$ th environment; $\mathrm{R}_{j(i)}$ is the effect of the $j$ th replication nested on the $i$ th environment; $\mathrm{G}_{k}$ is the effect of the $k$ th genotype, $\mathrm{EG}_{i k}$ is the effect of the interaction between the $i$ th environment and $k$ th genotype; and $\varepsilon_{i j k}$ is the effect of experimental error. G was set as a fixed effect when calculating BLUPs. Broad-sense heritability across all environments was calculated as:

$$
h^{2}=\frac{\sigma_{g}^{2}}{\sigma_{g}^{2}{ }^{+} \sigma_{g e}^{2} / i^{+} \sigma_{e}^{2} / i j}
$$

where $\sigma_{g}^{2}$ is the genotypic variance, $\sigma_{g e}^{2}$ is the genotype $\times$ environment interaction variance, $\sigma_{e}^{2}$ is the error variance, $i$ is the number of environments, and $j$ is the number of replications in each environment. All of the factors were set as random effects when calculating heritability. The violin plot was made using the ggplot2 package in $\mathrm{R}$ software [51] to show the distribution of phenotypic data for each population.

\section{Genotyping-by-Sequencing}

Young leaves of the three populations and parental lines were sampled. DNA extraction was performed using a CTAB method [52]. Genotypic data was generated using the genotyping-by-sequencing (GBS) method at Cornell University 
Biotechnology Resource Center (Ithaca, NY, USA). DNA sequencing was performed on Illumina HiSeq2000. TASSEL GBS Pipeline was used for SNP calling to align reads to maize B73 reference genome v2 (ZmB73_RefGen_v2). Imputation was carried out with the FILLIN method in TASSEL V5.0 [53, 54]. An imputed GBS dataset was used for GWAS and genomic prediction, while un-imputed GBS datasets were used for linkage mapping. A total of 955690 SNPs were obtained for each inbred line, and 570 of them could not be mapped to any of the 10 maize chromosomes. The number of SNPs on each chromosome ranged from 148752 on chromosome 1 to 67126 on chromosome 10 . SNPs with more than $20 \%$ missing rate, more than 0.05 heterozygosity, and less than 0.05 minor allele frequency (MAF) were excluded using filter function in TASSEL V5.0.

\section{Linkage disequilibrium, population structure, and genome-wide association} study

Linkage disequilibrium (LD) was analyzed by TASSEL V5.0 [54] with a sliding window size of 50 SNPs. Squared Pearson correlation coefficient $\left(r^{2}\right)$ between vectors of SNP alleles was used to assess the level of LD decay across each chromosome, and $r^{2}=0.1$ was used as a cutoff. Population structure was conducted using the STRUCTURE V2.3.4 software [55] to estimate the number of subgroups in the DTMA panel. The genotype data used was compressed by selecting 1 SNP per LD block [56]. The parameters were set as follows: length of burn-in period $=30,000$; number of MCMC reps after burn-in=30,000; ancestry model = use admixture model; allele frequency model $=$ allele frequency correlated; number of populations $(K)=1$ - 
10; and number of iterations $=10$. STRUCTURE HARVESTER

396 (http://taylor0.biology.ucla.edu/structureHarvester/) was used to visualizing

397 STRUCTURE V2.3.4 output and delta $K(\Delta K)$ value was used to determine the best $398 \quad \mathrm{k}$ value.

GWAS was conducted in the DTMA panel using the FarmCPU (Fixed and random model Circulating Probability Unification) method in GAPIT (Genome Association and Prediction Integrated Tool-R package) [57]. The kinship matrix $(K)$ and the first three principal components (PCs) from principal component analysis (PCA) were estimated by GAPIT to assess population structure to control false marker-trait association. The $P$-value of each SNP was calculated and the threshold level was defined at $P=3.70 \times 10^{-6}$ by a false discovery rate (FDR) correction method.

The sequence of each significant SNP was used to do BLAST against the ZmB73_RefGen_v2 genome sequence in MaizeGDB (http://www.maizegdb.org/). Genes containing or adjacent to each significant SNP were identified as the putative candidate genes. MaizeGDB database was used to annotate candidate genes.

\section{Linkage map construction and QTL mapping}

A Similarity/Linkage (SL) method was used for bin map construction with high

412 quality un-imputed SNPs in the two bi-parental DH populations described by Cao et al. [20]. In DH1, 437 bins were constructed by 31194 SNPs. In DH2, 503 bins were constructed by 37985 SNPs. Each bin was regarded as a genetic marker to construct genetic maps. Linkage map construction was conducted by MAP function in software 
QTL IciMapping V4.2 [58]. The whole length of the linkage map of DH1 was 988.56 $\mathrm{cM}$ with an average marker (bin) density of $2.26 \mathrm{cM}$. The genetic map of DH2 was $1539.78 \mathrm{cM}$ with an average distance of $3.06 \mathrm{cM}$ between adjacent markers (bins). An Inclusive composite interval mapping (ICIM) approach was conducted for linkage mapping analysis using the "BIP" function and the "ADD" mapping method in QTL IciMapping V4.2. A LOD (logarithm of the odds) score of 2 was used for declaring putative QTL. The additive effect and phenotypic variation explained (PVE) of each QTL were estimated.

\section{Genomic prediction}

Genomic prediction (GP) was conducted using the ridge regression best linear unbiased prediction (RRBLUP) model with the rrBLUP package [59] for all three populations. BLUPs across all environments were used for GP analysis. Genome-wide marker datasets including 187409, 53996, and 74450 SNPs were used for GP in DTMA panel, DH1, and DH2, respectively. The prediction accuracy within each population was estimated by a five-fold cross-validation method with 100 replications. GP accuracy was the average value of the correlation between the GEBVs and the observed phenotype values.

\section{Abbreviations}

DH: Doubled haploid (DH); GWAS: Genome-wide association study; GBS: Genotyping-by-sequencing; SNPs: Single-nucleotide polymorphisms; DH1: the first DH population; DH2: the second DH population; QTL: Quantitative trait loci; PVE: 
Phenotypic variation explained; CIMMYT: International Maize and Wheat Improvement Center; MAS: Marker-assisted selection; GP: Genomic prediction; GEBVs: Genomic estimated breeding values; DTMA: Drought Tolerant Maize for Africa; BLUPs: Best linear unbiased predictors; FarmCPU: Fixed and random model Circulating Probability Unification; GAPIT: Genome Association and Prediction Integrated Tool-R package; PCA: Principal component analysis; ICIM: Inclusive composite interval mapping; LOD: Logarithm of the odds; RRBLUP: Ridge regression best linear unbiased prediction

\section{Declarations}

\section{Acknowledgements}

Not applicable.

\section{Author's contributions}

BMP, MO, FSV, and XZ conceived and designed the experiments; AL, FSV, and XZ coordinated the phenotyping; XZ, BMP, MO coordinated the genotyping; JR, ZL, PW, AZ, YL, GH, SC, JQ, and HZ analyzed the data; JR, ZL, FSV, and XZ drafted the manuscript; JR, ZL, MO, BMP, FSV, and XZ interpreted the results.

\section{Funding}

The authors gratefully acknowledge the financial support from the MasAgro project funded by Mexico's Secretary of Agriculture and Rural Development (SADER), the Genomic Open-source Breeding Informatics Initiative (GOBII) (grant number: 
OPP1093167) supported by the Bill \& Melinda Gates Foundation, and the CGIAR Research Program (CRP) on MAIZE. The CGIAR Research Program MAIZE receives W1\&W2 support from the Governments of Australia, Belgium, Canada, China, France, India, Japan, Korea, Mexico, Netherlands, New Zealand, Norway, Sweden, Switzerland, U.K., U.S., and the World Bank. The authors also thank the CIMMYT-China Specialty Maize Research Center project funded by the Shanghai Municipal Finance Bureau, the National Natural Science Foundation of China (grant numbers: 32001561, 32060484, 31771814), Xinjiang Youth Foundation (grant number: 2019D01A41), Chinese Postdoc Foundation (grant numbers: 2018M643774, 2017M621318), the Chinese Postdoctoral International Exchange Program, the China Scholarship Council, Postdoctoral Science Foundation of Heilongjiang Province (grant number: LBH-Z17205), and the Fund for Distinguished Young Scholars of Heilongjiang Academy of Agricultural Sciences (grant number: 2019JCQN004).

\section{Availability of data and materials}

The datasets used and/or analyzed during the current study are available from the corresponding author on reasonable request.

\section{Ethics approval and consent to participate}

Not applicable.

\section{Consent for publication}

Not applicable. 


\section{Competing interests}

The authors declare that they have no conflict of interest.

\section{Author details}

${ }^{1}$ College of Agronomy, Xinjiang Agricultural University, Urumqi 830052, Xinjiang, China. ${ }^{2}$ International Maize and Wheat Improvement Center (CIMMYT), El Batan, Texcoco 56237, México. ${ }^{3}$ College of Agronomy, Henan Agricultural University, Zhengzhou 450002, Henan, China. ${ }^{4}$ College of Bioscience and Biotechnology, Shenyang Agricultural University, Shenyang 110866, Liaoning, China. ${ }^{5}$ Maize Research Institute, Heilongjiang Academy of Agricultural Sciences, Harbin 150086, Heilongjiang, China. ${ }^{6}$ Maize Research Institute, Sichuan Agricultural University, Wenjiang, Sichuan, China. ${ }^{7}$ CIMMYT-China Specialty Maize Research Center, Shanghai Academy of Agricultural Sciences 201403, Shanghai, China. ${ }^{8}$ Crop Breeding and Cultivation Research Institute, Shanghai Academy of Agricultural Sciences 201403, Shanghai, China. ${ }^{9}$ International Maize and Wheat Improvement Center (CIMMYT), P. O. Box 1041, Nairobi, Kenya.

\section{References}

1. Groth JV, Zeyen RJ, Davis DW, Christ BJ. Yield and quality losses caused by common rust (Puccinia sorghi Schw.) in sweet corn (Zea mays) hybrids. Crop Prot. $1983 ; 2: 105-11$ 
496

497

498

499

500

501

502

503

504

2. ChengY, Li J, Yao F, Long L, Wang Y, Wu Y, et al. Dissection of loci conferring resistance to stripe rust in Chinese wheat landraces from the middle and lower reaches of the Yangtze River via genome-wide association study. Plant Sci. 2019;287:110204.

3. Rossi EA, Ruiz M, Bonamico NC, Balzarini MG. Identifying inbred lines with resistance to endemic diseases in exotic maize germplasm. Crop Sci. 2020. https://doi.org/10.1002/csc2.20275.

4. Sserumaga JP, Makumbi D, Assanga SO, Mageto EK, Njeri SG, Jumbo BM, et al. Identification and Diversity of Tropical Maize Inbred Lines with Resistance to Common Rust (Puccinia sorghi Schwein). Crop Sci. 2020. https://doi.org/10.1002/csc2.20345.

5. Sucher J, Boni R, Yang P, Rogowsky P, Büchner H, Kastner C, et al. The durable wheat disease resistance gene Lr34 confers common rust and northern corn leaf blight resistance in maize. Plant Biotechnol. J. 2017;15:489-96.

6. Hooker AL. Corn and sorghum rusts. In: Roelfs AP, Bushnell WR, editors. The Cereal Rusts. Florida: Academic Press; 1985. p. 207-36.

7. Delaney DE, Webb CA, Hulbert SH. A novel rust resistance gene in maize showing overdominance. Mol. Plant Microbe In. 1988;11:242-5.

8. Lübberstedt $\mathrm{T}$, Klein $\mathrm{D}$, Melchinger AE. Comparative quantitative trait loci mapping of partial resistance to Puccinia sorghi across four populations of European flint maize. Phytopathology. 1988;88:1324-9. 
9. Zheng H, Chen J, Mu C, Makumbi D, Xu Y, Mahuku G. Combined linkage and association mapping reveal QTL for host plant resistance to common rust (Puccinia sorghi) in tropical maize, BMC Plant Biol. 2018;18:310.

10. Olukolu BA, Tracy WF, Wisser R, De Vries B, Balint-Kurti PJ. A genome-wide association study for partial resistance to maize common rust. Phytopathology. 2016;106:745-51.

11. Kerns MR, Dudley JW, Rufener GK. QTL for resistance to common rust and smut in maize. Maydica. 1999;44:37-45.

12. Brown AF, Juvik JA, Pataky JK. Quantitative trait loci in sweet corn associated with partial resistance to Stewart's wilt, northern corn leaf blight, and common rust. Phytopathology. 2001;91:293-300.

13. Han G, Li C, Xiang F, Zhao Q, Zhao Y, Cai R, et al. Genome-wide association study leads to novel genetic insights into resistance to Aspergillus flavus in maize kernels. BMC Plant Biol. 2020;20:206.

14. Zila CT, Ogut F, Romay MC, Gardner CA, Buckler ES, Holland JB. Genome-wide association study of Fusarium ear rot disease in the USA maize inbred line collection. BMC Plant Biol. 2014;14:372.

15. Yan J, Warburton M, Crouch J. Association mapping for enhancing maize (Zea mays L.) genetic improvement. Crop Sci. 2011;51:433-49.

16. Sun F, Liu J, Hua W, Sun X, Wang X, Wang H. Identification of stable QTLs for seed oil content by combined linkage and association mapping in Brassica napus. Plant Sci. 2016;252:388-99. 
538

539

540

541

542

17. Li X, Zhou Z, Ding J, Wu Y, Zhou B, Wang R, et al. Combined linkage and association mapping reveals QTL and candidate genes for plant and ear height in maize. Front. Plant Sci. 2016;7:833.

18. Wu X, Li Y, Shi Y, Song Y, Zhang D, Li C, et al. Joint-linkage mapping and GWAS reveal extensive genetic loci that regulate male inflorescence size in maize. Plant Biotechnol. J. 2016;14:1551-62.

19. Deng M, Li D, Luo J, Xiao Y, Liu H, Pan Q, et al. The genetic architecture of amino acids dissection by association and linkage analysis in maize. Plant Biotechnol. J. $2017 ; 15: 1250-63$.

20. Cao S, Loladze A, Yuan Y, Wu Y, Zhang A, Chen J, et al. Genome-wide analysis of tar spot complex resistance in maize using genotyping-by-sequencing SNPs and whole-genome prediction. Plant Genome. 2017;10:2.

21.] Suresh LM, Beyene Y, Olsen MS, Makumbi D, Oliver K, Das B, et al. Genetic architecture of maize chlorotic mottle virus and maize lethal necrosis through GWAS, linkage analysis and genomic prediction in tropical maize germplasm. Theor. Appl. Genet. 2019;132:2381-99.

22. Kibe M, Nyaga C, Nair SK, Beyene Y, Das B, Bright JM, et al. Combination of Linkage Mapping, GWAS, and GP to Dissect the Genetic Basis of Common Rust Resistance in Tropical Maize Germplasm. Int. J. Mol. Sci. 2020;21:6518.

23. Stevens R. Prospects for using marker-assisted breeding to improve maize production in Africa. J. Sci. Food Agr. 2008;88:745-55. 
560 Genome-wide association and genomic prediction of resistance to maize lethal

561 necrosis disease in tropical maize germplasm. Theor. Appl. Genet. 2015;128:1957-68.

25. Muleta KT, Pressoir G, Morris GP. Optimizing genomic selection for a sorghum breeding program in Haiti: a simulation study. G3: Genes, Genom. Genet. 2019;9:391-401.

26. Zhang A, Wang H, Beyene Y, Semagn K, Liu Y, Cao S, et al. Effect of trait heritability, training population size and marker density on genomic prediction accuracy estimation in 22 bi-parental tropical maize populations. Front. Plant Sci. 2017;8:1916.

27. An Y, Chen L, Li Y, Li C, Shi Y, Zhang D, et al. Genome-Wide Association Studies and Whole-Genome Prediction Reveal the Genetic Architecture of KRN in Maize. BMC Plant Biol. 2020;20:490.

28. Liu X, Yuan Y, Martinez C, Babu R, Suarez EA, Zhang X, et al. Identification of QTL for early vigor and leaf senescence across two tropical maize doubled haploid populations under nitrogen deficient conditions. Euphytica. 2020;216:42. study dissects the genetic architecture of oil biosynthesis in maize kernels. Nat. Genet. 2013;45:43-50.

30. Su C, Wang W, Gong S, Zuo J, Li S, Xu S. High density linkage map construction and mapping of yield trait QTLs in maize (Zea mays) using the genotyping-by-sequencing (GBS) technology. Front. Plant Sci. 2017;8:706. 
581

582

583

31. Hall D, Tegstrom C, Ingvarsson PK. Using association mapping to dissect the genetic basis of complex traits in plants. Brief. Funct. Genomics. 2010;9:157-65.

32. Pascual L, Desplat N, Huang BE, Desgroux A, Bruguier L, Bouchet JP, et al. Potential of a tomato MAGIC population to decipher the genetic control of quantitative traits and detect causal variants in the resequencing era. Plant Biotechnol. J. 2015;13:565-77.

33. Yu J, Buckler ES, Genetic association mapping and genome organization of maize. Curr. Opin. Biotechnol. 2006;17:155-60.

34. Wang H, Xu C, Liu X, Guo Z, Xu X, Wang S, et al. Development of a multiple-hybrid population for genome-wide association studies: theoretical consideration and genetic mapping of flowering traits in maize. Sci. Rep. 2017;7:40239.

35. Yu J, Pressoir G, Briggs WH, Bi IV, Yamasaki M, Doebley JF, et al. A unified mixed-model method for association mapping that accounts for multiple levels of relatedness. Nat. Genet. 2006;38:203-8.

36. Ren J, Boerman NA, Liu R, Wu P, Trampe B, Vanous K, et al. Mapping of QTL and identification of candidate genes conferring spontaneous haploid genome doubling in maize (Zea mays L.). Plant Sci.2020; 293:110337.

37. Famoso AN, Zhao K, Clark RT, Tung C, Wright MH, Kochian LV, et al. Genetic architecture of aluminum tolerance in rice (Oryza sativa) determined through genome-wide association analysis and QTL mapping. PLoS Genet. 2011;7:e1002221. 
602

603

604

605

606

607

608

609

610

611

612

613

614

615

616

617

618

619

620

621

38. Cadic E, Coque M, Vear F, Grezes-Besset B, Pauquet J, Piquemal J, et al. Combined linkage and association mapping of flowering time in Sunflower (Helianthus annuus L.). Theor. Appl. Genet. 2013;126:1337-56.

39. Kost MA, Perales H, Wijeratne S, Wijeratne AJ, Stockinger EJ, Mercer KL. Transcriptional differentiation of UV-B protectant genes in maize landraces spanning an elevational gradient in Chiapas, Mexico. Evol. Appl. 2020;13:1949-67.

40. Kim HR, Chae KS, Han KH, Han DM. The nsdC gene encoding a putative $\mathrm{C}_{2} \mathrm{H}_{2}$-type transcription factor is a key activator of sexual development in Aspergillus nidulans. Genetics. 2009;182:771-83.

41. Wang Y, Dou D, Wang X, Li A, Sheng Y, Hua C, et al. The PsCZF1 gene encoding a $\mathrm{C}_{2} \mathrm{H}_{2}$ zinc finger protein is required for growth, development and pathogenesis in Phytophthora sojae. Microb. Pathog. 2009;47:78-86.

42. Xiao H Tang J, Li Y, Wang W, Li X, Jin L, et al. STAMENLESS 1, encoding a single $\mathrm{C}_{2} \mathrm{H}_{2}$ zinc finger protein, regulates floral organ identity in rice. Plant $\mathrm{J}$. 2009;59:789-801.

43. Kiełbowicz-Matuk A. Involvement of plant $\mathrm{C}_{2} \mathrm{H}_{2}$-type zinc finger transcription factors in stress responses. Plant Sci. 2012;185:78-85.

44. Uehara Y, Takahashi Y, Berberich T, Miyazaki A, Takahashi H, Matsui K, et al. Tobacco ZFT1, a transcriptional repressor with a Cys 2/His 2 type zinc finger motif that functions in spermine-signaling pathway. Plant Mol. Biol. 2005;59:435-48. 
622

623

624

625

626

627

628

629

630

631

632

633

634

635

636

637

638

639

640

641

642

45. Kim SH, Hong JK, Lee SC, Sohn KH, Jung HW, Hwang BK. CAZFP1, $\mathrm{Cys}_{2} / \mathrm{His}_{2}$-type zinc-finger transcription factor gene functions as a pathogen-induced early-defense gene in Capsicum annuum. Plant Mol. Biol. 2004;55:883-904.

46. Cao H, Glazebrook J, Clarke JD, Volko S, Dong X. The Arabidopsis NPR1 gene that controls systemic acquired resistance encodes a novel protein containing ankyrin repeats. Cell. 1997;88:57-63.

47. Chern M, Fitzgerald HA, Canlas PE, Navarre DA, Ronald PC. Overexpression of a rice NPR1 homolog leads to constitutive activation of defense response and hypersensitivity to light. Mol. Plant Microbe In. 2005;18:511-20.

48. Silva KJ, Brunings A, Peres NA, Mou Z, Folta KM. The Arabidopsis NPR1 gene confers broad-spectrum disease resistance in strawberry. Transgenic Res. 2015;24:693-704.

49. Tayeh N, Klein A, Le Paslier MC, Jacquin F, Houtin H, Rond C, et al. Genomic prediction in pea: effect of marker density and training population size and composition on prediction accuracy. Front. Plant Sci. 2015;6:941.

50. Zhang X, Pérez-Rodríguez P, Semagn K, Beyene Y, Babu R, López-Cruz MA, et al. Genomic prediction in biparental tropical maize populations in water-stressed and well-watered environments using low-density and GBS SNPs. Heredity. $2015 ; 114: 291-9$

51. Team RC. R: A language and environment for statistical computing. 2020. https://www.r-project.org. Accessed 24 Jan 2020. 
643 644 protocols. 3rd ed. Mexico: CIMMYT; 2005.

645 53. Swarts K, Li H, Navarro JAR, An D, Romay MC, Hearne S, et al. Novel methods 646 to optimize genotypic imputation for low-coverage, next-generation sequence data in 647 crop plants. Plant Genome. 2014;7:3.

648

649

650

651

652

653

654

655

656

657

658

659

660

661

662

663

52. CIMMYT. CIMMYT Applied Molecular Genetics Laboratory, Laboratory 54. Bradbury PJ, Zhang Z, Kroon DE, Casstevens TM, Ramdoss Y, Buckler ES. TASSEL: software for association mapping of complex traits in diverse samples. Bioinformatics. 2007;23:2633-5.

55. Hubisz MJ, Falush D, Stephens M, Pritchard JK. Inferring weak population structure with the assistance of sample group information. Mol. Ecol. Resour. 2009;9:1322-32.

56. Duggal P, Gillanders EM, Holmes TN, Bailey-Wilson JE. Establishing an adjusted p-value threshold to control the family-wide type 1 error in genome wide association studies. BMC genomics 2008;9:516.

57. Lipka AE, Tian F, Wang Q, Peiffer J, Li M, Bradbury PJ, et al. GAPIT: genome association and prediction integrated tool. Bioinformatics. 2012;28:2397-9.

58. Wang J, Li H, Zhang L, Meng L. Users' manual of QTL IciMapping Version 4.2, Beijing: The Quantitative Genetics Group, Institute of Crop Science, Chinese Academy of Agricultural Sciences (CAAS), Beijing 100081, China, and Genetic Resources Program, International Maize and Wheat Improvement Center (CIMMYT), Apdo. Postal 6 - 641, 06600 Mexico, D.F., Mexico. 2019 
664 59. Endelman JB. Ridge regression and other kernels for genomic selection with R 665 package rrBLUP. Plant Genome. 2011;4:250-5. 
667 Table 1 Descriptive statistics, variance components, and broad-sense heritability $\left(H^{2}\right)$ response to

668 common rust in the Drought Tolerant Maize for Africa (DTMA) panel and two bi-parental 669 doubled haploid (DH) populations.

\begin{tabular}{|c|c|c|c|c|c|c|c|c|c|}
\hline \multirow{2}{*}{ Population } & \multirow{2}{*}{ Mean } & \multirow{2}{*}{ Min. } & \multirow{2}{*}{ Max. } & \multirow{2}{*}{ Median } & \multirow{2}{*}{$\mathrm{SD}^{\mathrm{a}}$} & \multicolumn{3}{|c|}{ Variance components ${ }^{\mathrm{b}}$} & \multirow{2}{*}{$h^{2 c}$} \\
\hline & & & & & & $\sigma_{g}^{2}$ & $\sigma_{g e}^{2}$ & $\sigma_{e}^{2}$ & \\
\hline DTMA & 2.32 & 1.26 & 4.13 & 2.30 & 0.52 & $0.33^{* *}$ & $0.25^{* *}$ & 0.24 & 0.80 \\
\hline DH1 & 2.25 & 1.73 & 3.10 & 2.20 & 0.23 & $0.10^{* *}$ & $0.08^{* *}$ & 0.20 & 0.57 \\
\hline $\mathrm{DH} 2$ & 2.27 & 1.76 & 3.16 & 2.32 & 0.26 & $0.08^{* *}$ & 0 & 0.09 & 0.84 \\
\hline
\end{tabular}

$670 \quad{ }^{a}$ SD, standard deviation

$671{ }^{\mathrm{b}} \sigma_{g}^{2}$, genotypic variance.

$672 \sigma_{g e}^{2}$, genotype $\times$ environment interaction variance.

$673 \sigma_{e}^{2}$, error variance.

$674 * *$ Significant at $\mathrm{P}<0.01$.

$675{ }^{\mathrm{c}} h^{2}$, broad-sense heritability. 
676 Table 2 Summary information of GBS-derived SNPs in the Drought Tolerant Maize for Africa 677 (DTMA) panel and two bi-parental doubled haploid (DH) populations before and after filter.

678

\begin{tabular}{ccccccccc}
\hline \multirow{2}{*}{ Population } & \multicolumn{2}{c}{ No. of SNPs } & Missing rate(\%) & $\begin{array}{c}\text { Heterozygosity } \\
\text { rate(\%) }\end{array}$ & $\begin{array}{c}\text { Average minor allele } \\
\text { frequency }\end{array}$ \\
\cline { 2 - 9 } & $\begin{array}{c}\text { Before } \\
\text { filter }\end{array}$ & $\begin{array}{c}\text { After } \\
\text { filter }\end{array}$ & $\begin{array}{c}\text { Before } \\
\text { filter }\end{array}$ & $\begin{array}{c}\text { After } \\
\text { filter }\end{array}$ & $\begin{array}{c}\text { Before } \\
\text { filter }\end{array}$ & $\begin{array}{c}\text { After } \\
\text { filter }\end{array}$ & Before filter & After filter \\
& 955690 & 187409 & 15.79 & 7.33 & 1.49 & 2.83 & 0.09 & 0.18 \\
DTMA & 955690 & 31194 & 42.53 & 9.73 & 0.39 & 3.17 & 0.04 & 0.42 \\
DH1 & 955690 & 37985 & 42.29 & 8.66 & 0.36 & 2.64 & 0.04 & 0.42 \\
\hline
\end{tabular}


679 Table 3 Significantly associated SNP markers identified in the Drought Tolerant Maize for 680 Africa (DTMA) panel by GWAS analysis.

\begin{tabular}{|c|c|c|c|c|c|c|}
\hline $\mathrm{SNP}^{\mathrm{a}}$ & $P$-value & Allele & $\mathrm{IAF}^{\mathrm{c}}$ & SNP effect ${ }^{\mathrm{d}}$ & ${ }^{1}$ Putative Candidate Gene & $\begin{array}{l}\text { Annotation of Candidate } \\
\text { Genes }\end{array}$ \\
\hline S1_89238026 & $9.81 \times 10^{-10}$ & $\mathrm{~A} / \mathrm{G}$ & 0.32 & 0.13 & GRMZM2G114893 & $\begin{array}{l}\text { Zinc finger (C2H2 type) } \\
\text { family protein }\end{array}$ \\
\hline S1_278132829 & $7.25 \times 10^{-11}$ & $\mathrm{~A} / \mathrm{T}$ & 0.25 & 0.13 & GRMZM2G328500 & $\begin{array}{l}\text { UDP-glucose } \\
\text { 6-dehydrogenase }\end{array}$ \\
\hline S3_118933375 & $1.00 \times 10^{-6}$ & $\mathrm{C} / \mathrm{T}$ & 0.10 & -0.17 & GRMZM2G144004 & Unknown \\
\hline S3_147594533 & $1.11 \times 10^{-7}$ & $\mathrm{~A} / \mathrm{T}$ & 0.11 & 0.15 & GRMZM2G162250 & Zea mays ARGOS6 \\
\hline S4_183913302 & $2.98 \times 10^{-7}$ & $\mathrm{G} / \mathrm{C}$ & 0.17 & 0.13 & GRMZM2G138949 & $\begin{array}{l}\text { BTB/POZ domain-containing } \\
\text { protein }\end{array}$ \\
\hline S10_95231291 & $1.32 \times 10^{-7}$ & $\mathrm{C} / \mathrm{A}$ & 0.10 & -0.16 & GRMZM2G131536 & Unknown \\
\hline
\end{tabular}

681 a SNP name, chromosome_position, for example, S1_89238026 represents the SNP is on 682 chromosome 1 , the physical position is $89238026 \mathrm{bp}$.

$683 \mathrm{~b}$ Letters to the left and right of the "/" refer to major allele and minor allele, respectively.

$684{ }^{\mathrm{c}} \mathrm{MAF}$, minor allele frequency.

$685 \mathrm{~d}$ Positive values indicate that the major allele is a resistance allele; negative values indicate that 686 the minor allele is a resistance allele. 
687 Table 4 QTL identified in the two bi-parental doubled haploid (DH) populations.

\begin{tabular}{|c|c|c|c|c|c|c|}
\hline \multicolumn{2}{|c|}{ Population Chromosome } & \multirow{2}{*}{$\begin{array}{l}\text { Left Marker (position) }^{\mathrm{a}} \\
\text { C1M16 (31534594) }\end{array}$} & \multirow{2}{*}{$\begin{array}{l}\text { Right Marker (position) } \\
\text { C1M17 (34176396) }\end{array}$} & \multirow{2}{*}{$\frac{\mathrm{LOD}^{\mathrm{b}}}{6.77}$} & \multirow{2}{*}{$\frac{\operatorname{PVE}(\%)^{\mathrm{c}}}{10.34}$} & \multirow{2}{*}{$\begin{array}{c}\text { Additive effect } \\
-0.08\end{array}$} \\
\hline DH1 & 1 & & & & & \\
\hline & 2 & C2M88 (184258186) & C2M89 (187894077) & 3.49 & 5.69 & 0.06 \\
\hline & 4 & C4M185 (185251502) & C4M186 (186037532) & 4.62 & 6.79 & 0.06 \\
\hline & 6 & C6M253 (9362045) & C6M254 (22037035) & 2.42 & 3.55 & 0.05 \\
\hline & 7 & C7M315 (144585945) & C7M316 (149528489) & 7.82 & 12.45 & 0.09 \\
\hline & 9 & C9M371 (1265981) & C9M372 (2794057) & 3.70 & 5.40 & -0.06 \\
\hline \multirow[t]{2}{*}{ DH2 } & 1 & C1M93 (253500195) & C1M95 (254447195) & 2.18 & 8.33 & -0.08 \\
\hline & 3 & C3M246 (10598765) & C3M248 (12632347) & 2.27 & 8.80 & -0.08 \\
\hline
\end{tabular}

\footnotetext{
688 a Marker name, chromosome_bin, For example, C1M16 represents the 16th bin on chromosome 1 689 and the physical position is $31,534,594$.

$690 \quad{ }^{b}$ LOD, logarithm of the odds.

$691 \quad{ }^{\mathrm{c}}$ PVE, phenotypic variation explained.
} 


\section{Figure legends}

693 Fig.1 Violin plots of common rust scores in the (a) Drought Tolerant Maize for Africa (DTMA) 694 panel, DH1, and DH2 and (b) subgroups of the DTMA panel.

695 Fig.2 Linkage disequilibrium decay across all 10 maize chromosomes in the Drought Tolerant 696 Maize for Africa (DTMA) panel.

697 Fig.3 Population structure of the genome-wide association study (GWAS) panel. (A) the plot of 698 delta k calculated for $k=2$ - 9. (B) Population structure estimated for the GWAS panel at $K=4$.

699 Fig.4 Genome-wide association study (GWAS) manhattan plot for common rust resistance in the 700 Drought Tolerant Maize for Africa (DTMA) panel. The dash line correspond to the threshold level 701 defined at $\mathrm{P}=3.70 \times 10^{-6}$ by a false discovery rate (FDR) correction method.

702 Fig.5 Plot of LOD scores of quantitative trait loci (QTL) analysis for common rust resistance 703 across 10 maize chromosomes in the two bi-parental doubled haploid (DH) populations.

704 Fig.6 Genomic prediction accuracy of common rust resistance in the Drought Tolerant Maize for 705 Africa (DTMA) panel, DH1, and DH2. 
Figures
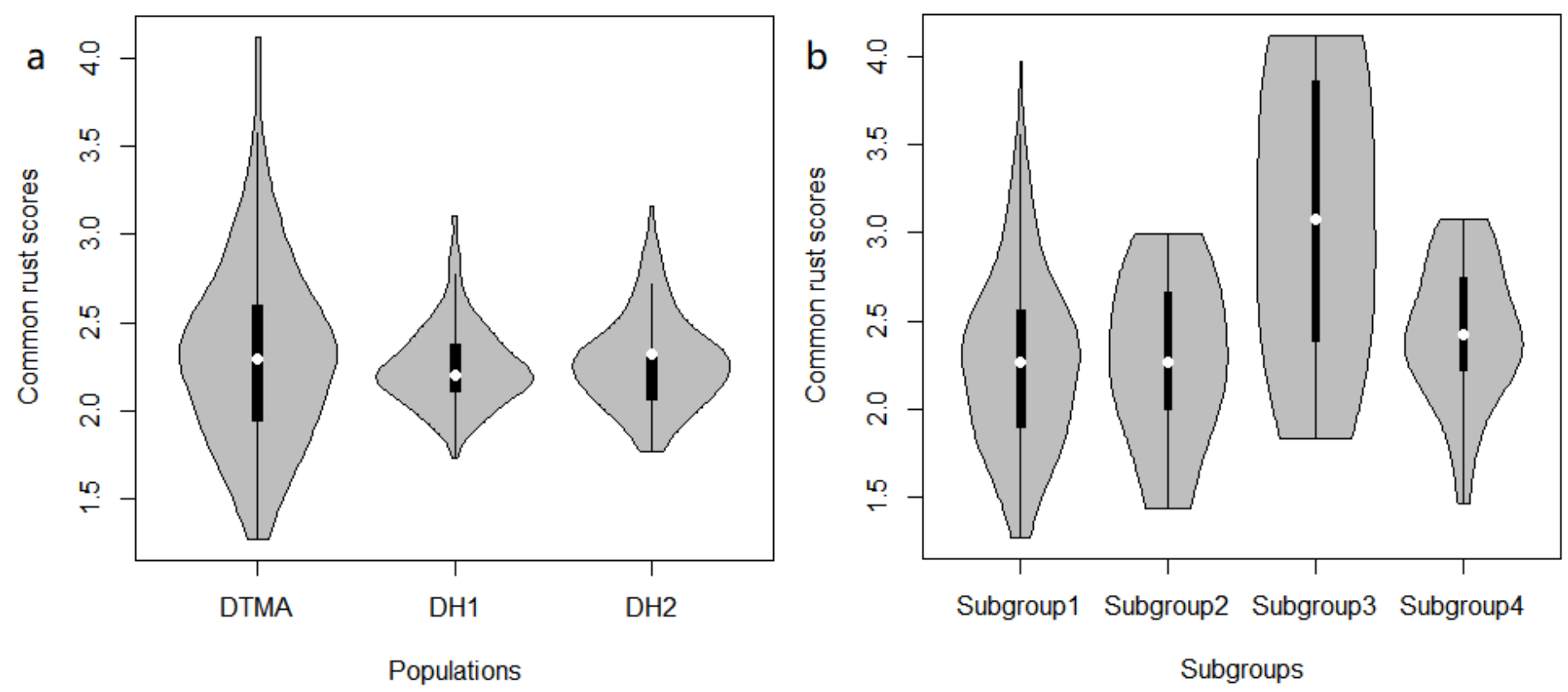

Figure 1

Violin plots of common rust scores in the (a) Drought Tolerant Maize for Africa (DTMA) panel, DH1, and $\mathrm{DH} 2$ and (b) subgroups of the DTMA panel. 


\section{LD Decay Plot}

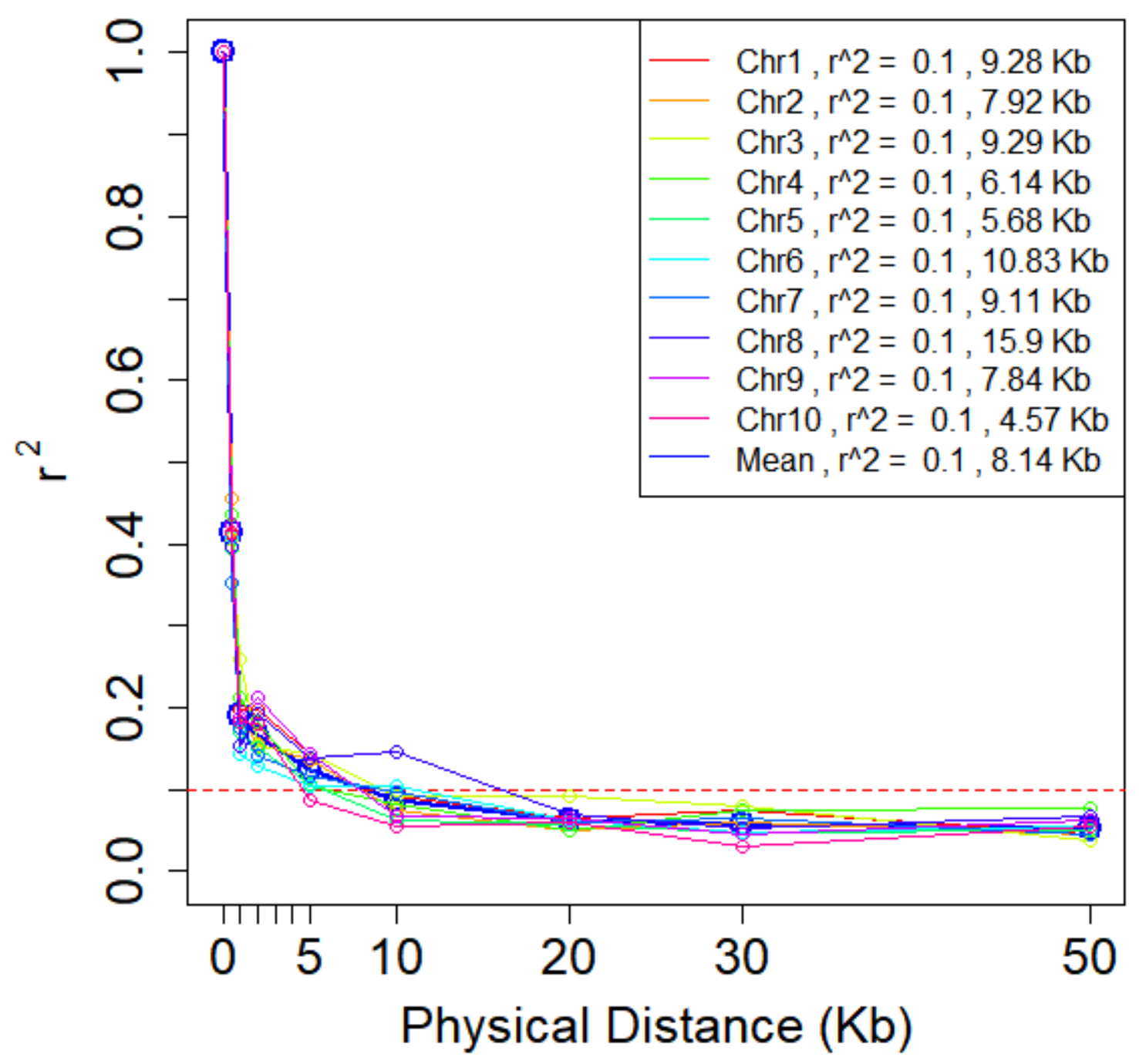

Figure 2

Linkage disequilibrium decay across all 10 maize chromosomes in the Drought Tolerant Maize for Africa (DTMA) panel. 

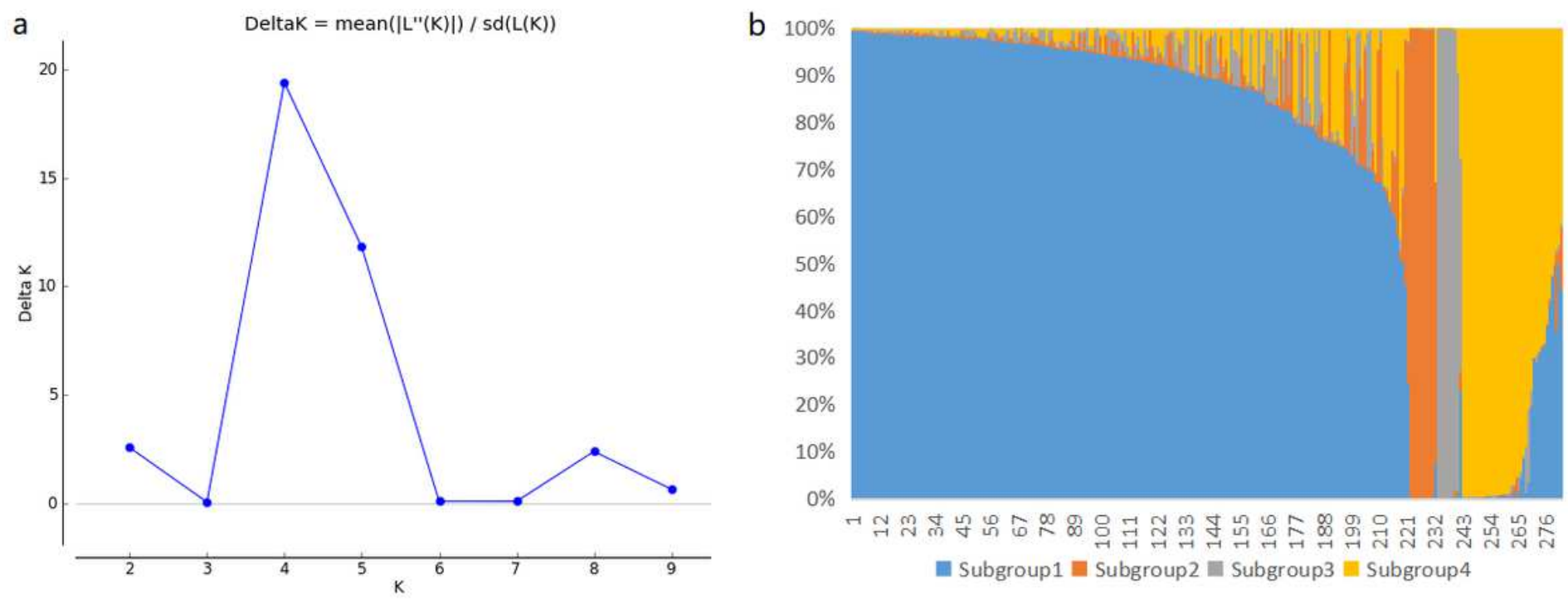

\section{Figure 3}

Population structure of the genome-wide association study (GWAS) panel. (A) the plot of delta $k$ calculated for $\mathrm{k}=2$ - 9. (B) Population structure estimated for the GWAS panel at $\mathrm{K}=4$.

\section{BLUP_CR}

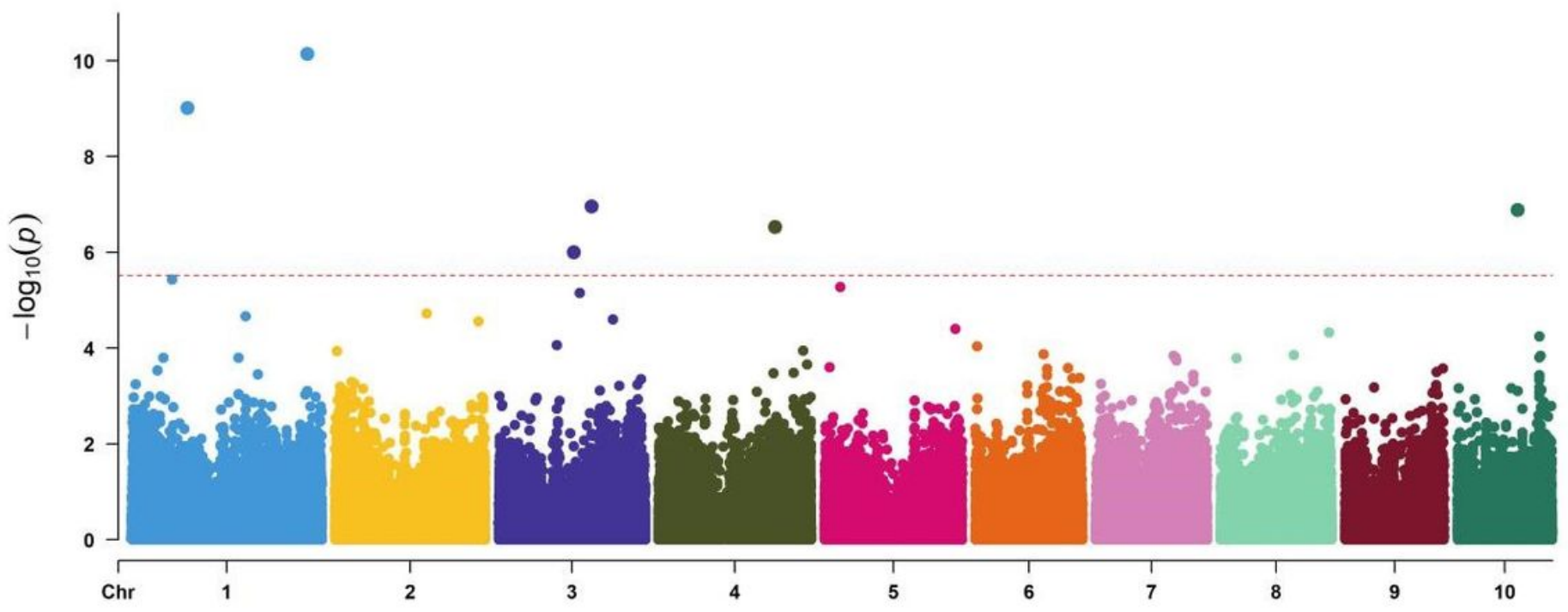

\section{Figure 4}

Genome-wide association study (GWAS) manhattan plot for common rust resistance in the Drought Tolerant Maize for Africa (DTMA) panel. The dash line correspond to the threshold level defined at $P=$ $3.70 \times 10-6$ by a false discovery rate (FDR) correction method. 

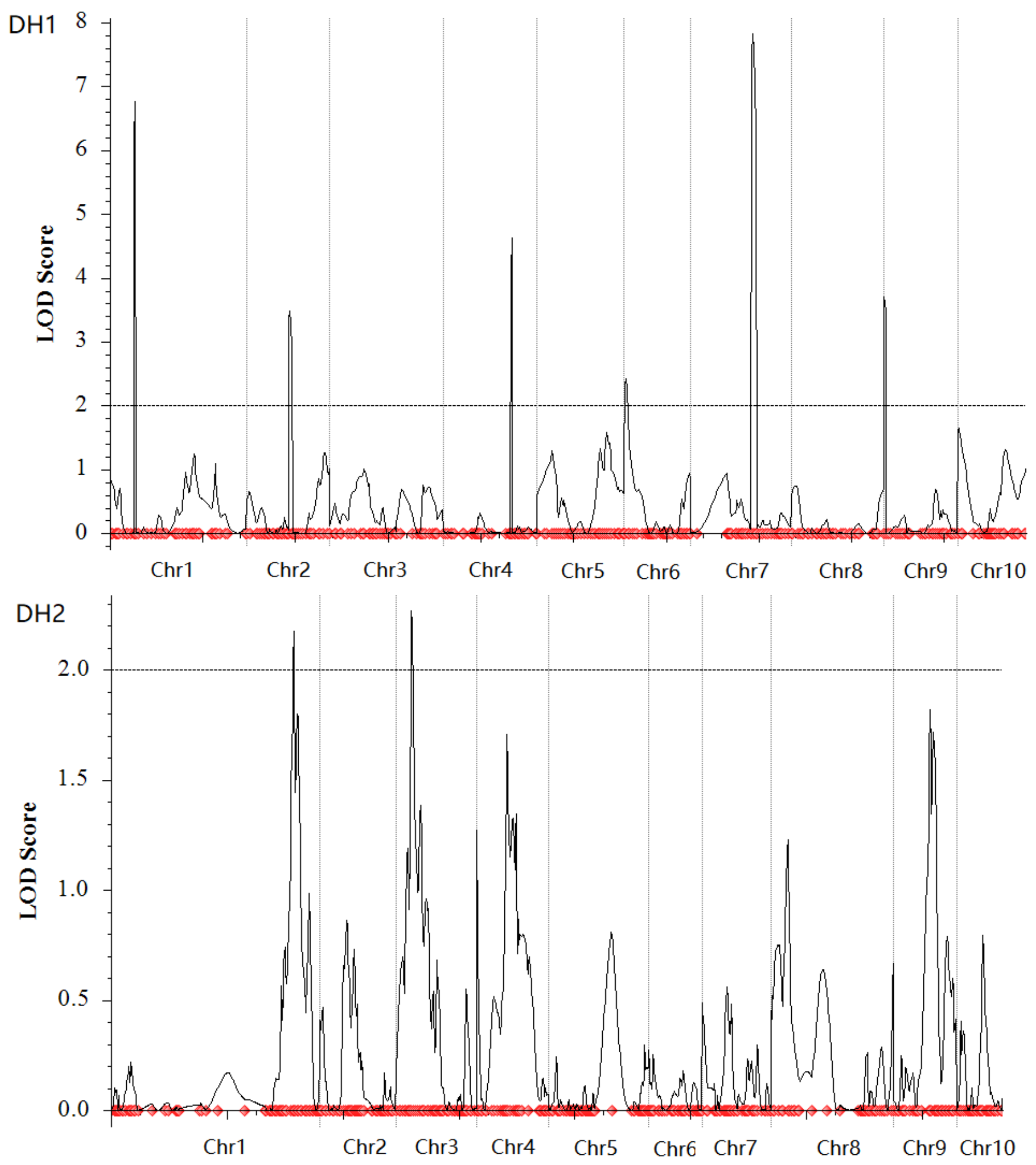

Figure 5

Plot of LOD scores of quantitative trait loci (QTL) analysis for common rust resistance across 10 maize chromosomes in the two bi-parental doubled haploid (DH) populations. 


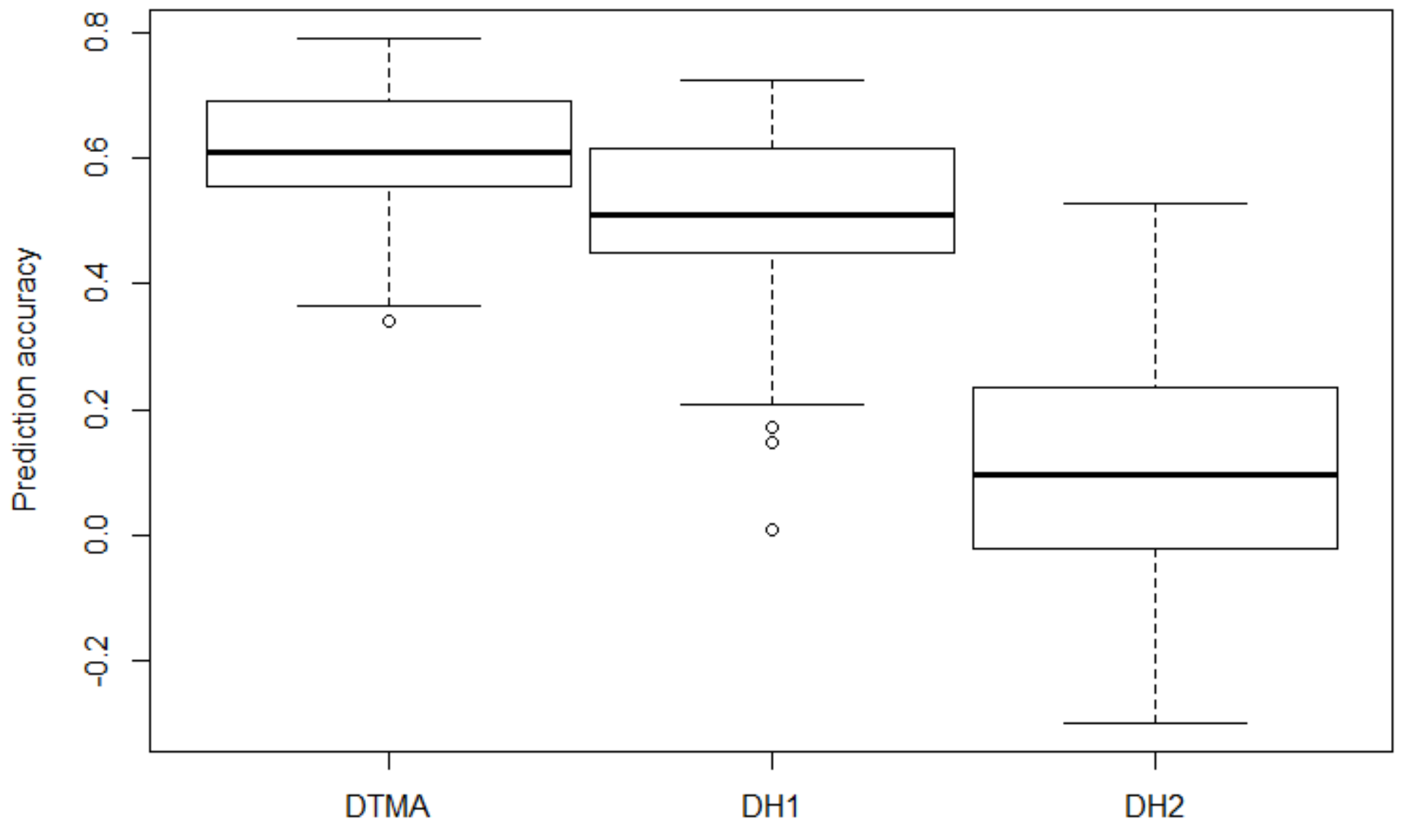

Population

Figure 6

Genomic prediction accuracy of common rust resistance in the Drought Tolerant Maize for Africa (DTMA) panel, DH1, and DH2. 